\title{
Os capitães-mores do Pará (1707-1737): trajetórias, governo e dinâmica administrativa no Estado do Maranhão
}

\author{
Fabiano Vilaça dos Santos*
}

\section{RESUMO}

O artigo aborda as trajetórias no Real Serviço de seis capitães-mores que governaram a capitania do Pará na primeira metade do século XVIII. Contempla a caracterização dos perfis individuais, os critérios de seleção dos agentes (com base em suas experiências na Europa e no Atlântico português) e expóe, em linhas gerais, o exercício da governação. $\mathrm{O}$ trabalho investe, ainda, em uma discussão sobre a dinâmica administrativa na jurisdição do Estado do Maranhão e Grão-Pará, com ênfase nos deslocamentos dos governadores e capitães-generais da sede do governo, em São Luís, para Belém. Verificada a partir da segunda metade do século XVII, essa particularidade da estrutura político-administrativa do Estado do Maranhão estava respaldada nas conjunturas da colonização das conquistas do Norte e chegou a termo em 1751, quando a capital do Estado foi transferida definitivamente para Belém.

Palavras-chave: Capitães-mores; Pará; trajetórias; dinâmica administrativa; Estado do Maranhão.

\section{ABSTRACT}

The paper discusses the careers in the Royal Service of six captain-generals, who governed the State of Maranhão and Grão-Pará in the first half of the eighteenth century. It characterizes individual profiles, and the criteria to select agents (based on their experiences in Europe and in the Portuguese Atlantic), offering an overview of the exercise of governance. The paper also examines the dynamics in the administrative jurisdiction of the State of Maranhão and Grão Pará, emphasizing the frequent trips of governors and captain-generals from São Luís, government headquarters, to Belém. Recorded since the second half of the seventeenth century, this peculiarity of the political and administrative structure of the State of Maranhão and Grão-Pará was warranted by the need to conquest and colonize the North, and came to an end in 1751, when the state capital was definitely moved to Belém.

DOI - http://dx.doi.org/10.1590/2237-101X016031013

Artigo recebido em 30 de abril de 2015 e aprovado para publicação em 1 de setembro de 2015.

* Doutor em História Social pela Universidade de São Paulo (USP) e professor na Universidade do Estado do Rio de Janeiro (Uerj). Rio de Janeiro, RJ, Brasil. E-mail: fabianovilaca@gmail.com. 
Keywords: captain-generals; Pará; trajectories; administrative dynamics; State of Maranhão and Grão-Pará.

\section{Introdução}

O artigo apresenta resultados de pesquisa relacionados com uma investigação mais ampla sobre as trajetórias sociais e administrativas de oito governadores e capitães-generais do Estado do Maranhão e Grão-Pará, na primeira metade do século XVIII. Nos levantamentos preliminares também foram identificados os capitães-mores da capitania subalterna do Pará (o Maranhão era a cabeça da repartição subordinada a Lisboa). Entre 1707 e 1737, ou seja, durante boa parte do reinado de d. João V, seis indivíduos exerceram o governo do Pará: Pedro Mendes Tomás (1707-1710); João de Barros da Guerra (1710-1716); José Velho de Azevedo (1716-1720); Manuel de Madureira Lobo (1720-1723); ${ }^{1}$ Antônio Marreiros (17281732) e Antônio Duarte de Barros (1732-1737).

Definida a amostragem, cabe ressaltar que esse estudo segue procedimentos e parâmetros teórico-metodológicos pertinentes à escrita biográfica, ${ }^{2}$ observando-se aspectos sociais (origem familiar, local de nascimento, ostentação ou não de símbolos de distinção pessoal) e profissionais (formação e experiências no Real Serviço), na medida do que foi possível extrair das fontes consultadas. Esses elementos deram subsídios à caracterização dos perfis individuais e à apreciação do processo de seleção dos agentes considerados.

\footnotetext{
${ }^{1} \mathrm{O}$ interregno entre 1723 e 1728 se explica pelo fato de Manuel de Madureira Lobo ter sido preso pelo governador e capitấo-general João da Maia da Gama, em 1723. Arquivo Histórico Ultramarino (doravante AHU). Códice 209, fl. 17-17v. Pela carta régia de 18 de abril de 1724, d. João V determinou que Manuel de Madureira Lobo permanecesse detido até o fim do seu triênio e depois remetido para o reino. AHU. Códice 269 (numeração da folha ilegível). Pelas provisóes de 22 de novembro de 1723 e de 24 de janeiro de 1725, João da Maia da Gama encarregou, respectivamente, os antigos capitães-mores José Velho de Azevedo e Pedro Mendes Tomás do governo da capitania do Pará. Fundação Biblioteca Nacional (doravante FBN). Divisão de Manuscritos. I - 31, 20, 020. PERES, Leonardo Ferreira. Mapa cronológico-histórico dos governadores e capitães-generais, dos governadores e capitães-mores que têm governado o Estado do Grão-Pará. Belém, 1812-1820. A situação só se normalizou em 1728, quando o tenente-general José Velho de Azevedo entregou o cargo a Antônio Marreiros. Cf. BAENA, Antônio Ladislau Monteiro. Compêndio das eras da província do Pará. Belém: Tipografia de Santos \& Santos Menor, 1838, p. 215. A informação do autor contradiz a ordem das nomeaçóes feitas por João da Maia da Gama, segundo o mapa de Leonardo Ferreira Peres. Além disso, Baena não mencionou Manuel de Madureira Lobo como capitão-mor (p. 203-215), assim como Varnhagen, que o omitiu em uma lista dos capitães-mores do Pará. Cf. História Geral do Brasil. Rio de Janeiro: E. \& H. Laemmert, 1857, t. 2, p. 457. Agradeço ao Prof. Dr. Rafael Chambouleyron (UFPA) a gentileza de me fornecer cópias digitalizadas de códices do Arquivo Público do Estado do Pará e do AHU.

${ }^{2}$ Cf. STONE, Lawrence. Prosopography. Daedalus, v. 100, p. 46, 1971. Apud. CHARLE, Christophe. A prosopografia ou biografia coletiva: balanço e perspectivas. In: HEINZ, Flávio M. (Org.). Por outra história das elites. Rio de Janeiro: FGV, 2006, p. 41. Ver também STONE, Lawrence. Prosopography. The Past \& Present. Boston/Londres, p. 45, 1981.
} 
A abordagem, em linhas gerais, do exercício da função governativa constituiu outra etapa da construção das trajetórias. Por fim, os deslocamentos dos governadores e capitáes-generais de São Luís para Belém deram ensejo à análise preliminar de uma dinâmica administrativa própria do Estado do Maranháo e Grão-Pará, encetada na década de 1670 e consubstanciada na decisão régia de criar, em 1751, o Estado do Grão-Pará e Maranhão.

\section{Trajetórias e serviços}

A exposição das folhas de serviços e dos percursos dos seis capitães-mores do Pará foi organizada segundo a ordem de sucessáo no governo da capitania, independentemente da antiguidade das açóes relatadas nos papéis que subsidiaram a sua escolha para o cargo.

Pedro Mendes Tomás, natural de Belém, dedicou-se às armas e ocupou diversos cargos importantes na administração do Estado do Maranhão. Em sua carta patente consta ter sido, entre 1673 e 1705, soldado, alferes e capitão de artilharia, provedor da Fazenda da capitania e provedor-mor da Fazenda do Estado do Maranhão. Morava havia mais de 35 anos em terras próximas do rio Moju, doadas pelos sogros, onde mantinha roças, lavouras e "arvoredo de cacau". ${ }^{3}$ Como nas demais trajetórias e consoante a retórica da concessão de mercês régias, o valor de seus préstimos foi realçado de modo a justificar a promoçáo a capitão-mor (era sargento-mor de infantaria no Pará). Reputado como "muito desembaraçado e limpo de mãos", teria merecido a aprovação de diferentes governadores e capitães-generais do Estado do Maranhão, aos quais sempre obedecera "sem reparar na perda que recebia em a sua fazenda por não faltar o que convinha ao meu Serviço". ${ }^{4}$

Diferentemente de Pedro Mendes Tomás, que construiu toda a sua trajetória no Estado do Maranhão, os percursos e as experiências dos outros capitáes-mores foram mais diversificados. Joáo de Barros da Guerra esteve cerca de três anos e meio em Angola, para onde foi em companhia do governador Gonçalo da Costa de Alcáçova Carneiro de Meneses (16911694), atuando como soldado infante e de cavalaria e cabo de esquadra da tropa de couraças da guarnição local. Entre 1703 e 1709, serviu em Lisboa, onde nasceu, como alferes, ajudante supra e do número, capitáo de infantaria do terço comandado pelo mestre de campo D. Miguel Carlos de Távora, 2oㅡ conde de Sáo Vicente, e lutou com distinção na Guerra da

\footnotetext{
${ }^{3}$ Em relação a essas terras, Pedro Mendes Tomás dirigiu uma petição ao governador e capitão-general Cristóvão da Costa Freire para a concessão de carta de sesmaria. Arquivo Nacional da Torre do Tombo (doravante ANTT). Registro Geral de Mercês. D. João V. Livro 6, fl. 147. A carta de confirmaçáo foi passada a 25 de janeiro de 1714; Chancelaria de D. João V. Livro 40, fl. 51-52. Ver também Arquivo Público do Estado do Pará (doravante APEP). Sesmarias. Livro 2, fl. 183.

${ }^{4}$ ANTT. Chancelaria de D. Pedro II. Livro 30, fl. 348-348v. Carta patente de 1o de junho de 1706. AHU. Maranhão (avulsos). Caixa 10, D. 1074.
} 
Sucessão Espanhola (1703-1714). Participou da restauração da vila de Monsanto, do cerco a Albuquerque, socorreu Arronches, no Alentejo, e assistiu à rendição de Badajoz. ${ }^{5}$

Nascido em Almeida, na Beira, José Velho de Azevedo tinha uma longa folha de serviços em Portugal e na América. Foi soldado em sua província natal e ajudante engenheiro das fortificaçóes de Trás-os-Montes. Em 1693 foi nomeado sargento-mor do Pará com exercício de engenheiro, trabalhando na região do Gurupá, além de empreender “jornadas fora da terra à sua custa sem ajuda de custo alguma de minha Fazenda, mas antes deu para o serviço uma canoa". Seis anos depois, recebeu a patente de sargento-mor engenheiro (ad honorem) do Rio de Janeiro, sendo incumbido de concluir reparos nas suas fortificaçôes. ${ }^{6}$

José Velho de Azevedo provinha de uma família de engenheiros militares. Seu pai, Jerônimo Velho de Azevedo, foi engenheiro ajudante das fortificações, capitão de infantaria, sargento-mor (ad honorem) e trabalhou no desenho das fortificaçóes da Beira e de Trás-os-Montes. ${ }^{7}$ Em 1702, foi promovido a tenente-general de artilharia, sendo encarregado de reparar as fortificaçóes do Cabo do Norte. Projetou o fosso e um baluarte na fortaleza do Gurupá e treinou os seus artilheiros. Substituiu Hilário de Sousa de Azevedo no cargo de capitão-mor do Pará (1696-1698), ocasião em que voltou a acudir as fortificações do Cabo do Norte, assoladas pelos franceses de Caiena, e as do Gurupá. Por volta de 1707, chegando ao conhecimento do governador do Estado do Maranhão a notícia de que a França havia preparado uma armada de guerra com destino à América, José Velho contribuiu para a defesa de São Luís com "paus para a estacada da marinha daquela praça, emprestando alguns negros todas as vezes que se lhe pediram para o meu Real Serviço". ${ }^{8}$

No Pará, antes de ser capitão-mor, além de oferecer seus préstimos e cabedais à Coroa, cultivou interesses particulares. Como atesta a concessão, em 1704, de uma carta de sesmaria relativa a três léguas e meia de terras onde possuía um engenho real de açúcar e mais légua e meia que pediu, pois as que ocupava já estavam desgastadas pelo prolongado uso. Uma carta de confirmação de sesmaria obtida em 1722, após petição encaminhada ao governador e capitão-general Bernardo Pereira de Berredo e Castro, atesta que José Velho de

\footnotetext{
${ }^{5}$ ANTT. Chancelaria de D. João V. Livro 34, fl. 88-89v. Carta patente de 26 de outubro de 1709.

${ }^{6}$ ANTT. Chancelaria de D. Pedro II. Livro 50, fl. 161; Chancelaria de D. Pedro II. Livro 53, fl. 94v. Carta patente de 24 de janeiro de 1699; Chancelaria de D. João V. Livro 44, fl. 58-59.

${ }^{7}$ Por seus serviços, Jerônimo Velho de Azevedo pediu e recebeu mercês para três filhas e o hábito da Ordem de Cristo para o primogênito, Antônio Velho de Azevedo. ANTT. Registro Geral de Mercês. D. Pedro II. Livro 1, fl. 326v; Chancelaria da Ordem de Cristo. Livro 79, fl. 235v-236v. Antônio Velho de Azevedo também seguiu a profissão do pai. Cf. CAETANO, Joaquim Oliveira; SOROMENHO, Miguel Conceição (estudos); FERREIRA, Teresa A. S. Duarte; SILVA, Ana Cristina de Santana; MARTINS, Lígia de Azevedo (textos). A ciência do desenho: a ilustração na coleção de códices da Biblioteca Nacional. Lisboa: Biblioteca Nacional, 2001, p. 23. Ver também ANTT. Registro Geral de Mercês. D. João V. Livro 17, fl. 120-120v.

${ }^{8}$ ANTT. Chancelaria de D. Pedro II. Livro 62, fl. 381-381v. Carta patente de 15 de março de 1702; Chancelaria de D. João V. Livro 44, fl. 58-59; Registro Geral de Mercês. D. João V. Livro 8, fl. 5-5v. Carta patente de 4 de fevereiro de 1716.
} 
Azevedo possuía meia légua de terra no sítio de Guarapiranga, "no Igarapé que chamam de Peris", com lavouras de cacau e currais de gado.?

Natural de Chaves, o transmontano Manuel de Madureira Lobo foi nomeado capitão-mor do Pará em reconhecimento de ações militares nas províncias do Alentejo e de Trás-os-Montes, de 1679 a 1719. Durante a Guerra da Sucessáo Espanhola galgou diversos postos. No momento em que recebeu a indicação para o governo ultramarino estava reformado como capitão de infantaria de um dos Regimentos da Corte. ${ }^{10}$

Antônio Marreiros assumiu o governo em 1728, após algumas interinidades. Nascido em Lisboa, alcançou o posto de sargento-mor de infantaria do Pará em 1719, amparado em mais de 30 anos de feitos militares na Beira, no Alentejo, em diversas expediçóes marítimas e na Guerra da Sucessão Espanhola. Entre 1683 e 1716 embarcou em cinco armadas, comboiando frotas ou socorrendo fortificaçóes na barra de Lisboa. Na Guerra da Sucessão Espanhola, pelejou em Arronches e em Valência de Alcântara, episódio em que foi ferido na perna direita por um estilhaço de granada. ${ }^{11} \mathrm{~A}$ mercê do cargo de capitão-mor do Pará levou em consideração os segundos serviços de Antônio Marreiros (de 1716 a 1725), incluindo o período em que foi sargento-mor de infantaria no Pará, tendo desempenhado com valor, segundo a sua carta patente, as suas obrigaçôes militares e as do governo interino da capitania, empenhando-se, por exemplo, na conclusão das “obras da Sé, as quais assistiu pessoalmente como também ao conserto das ruas por onde havia [de] passar a solene procissão do Corpo de Deus gastando para esse efeito da sua fazenda com os índios”. Consta, ainda, que nesse tempo manteve a capitania "sempre em tão boa paz e tranquilidade que sem faltar a Justiça, nunca houve dele queixa alguma mas sim muito que louvar do seu procedimento". ${ }^{2}$

Ao contrário dos outros capitães-mores, não há muitas informações sobre a trajetória de Antônio Duarte de Barros, em contraste com sua rumorosa gestão no Pará, sobretudo quando exerceu interinamente o cargo de governador e capitão-general do Estado do Maranhão, após a morte repentina de José da Serra, em 1736. Sabe-se que Antônio Duarte de Barros, de origem algarvia (nasceu em Faro), era capitão de infantaria do Regimento de Setúbal na altura em que recebeu a patente de capitão-mor do Pará. ${ }^{13}$ Ao requerer o pagamento de seus

\footnotetext{
${ }_{9}^{9}$ ANTT. Chancelaria de D. João V. Livro 60, fl. 64-65; Registro Geral de Mercês. D. João V. Livro 13, fl. 285. APEP. Sesmarias. Livro 1, fl. 89. Ver também CUNHA, Ana Paula Macedo. Engenhos e engenhocas: atividade açucareira no Estado do Maranhão e Grão-Pará (1706-1750). Dissertação (mestrado em História Social da Amazônia) - Programa de Pós-graduação em História Social da Amazônia, Universidade Federal do Pará, Belém, 2009, p. 40. Os interesses privados de José Velho de Azevedo também podem ser conhecidos por meio de seu testamento. Além de um engenho e de plantaçóes de cacau, possuía terrenos e casas de morada em Belém. Instituto de Estudos Brasileiros - Universidade de São Paulo. Coleção Alberto Lamego. Cód. 43.107. Ver também AHU. Pará (avulsos). Caixa 22, D. 2069.

${ }^{10}$ ANTT. Registro Geral de Mercês. D. João V. Livro 11, fl. 280-280v. Carta patente de 6 de março de 1720.

${ }^{11}$ ANTT. Chancelaria de D. João V. Livro 52, fl. 292v-293v.

${ }^{12}$ ANTT. Registro Geral de Mercês. D. João V. Livro 10, fl. 489-489v. Carta patente de 19 de maio de 1727. Ver também APEP. Sesmarias. Livro 5, fl. 17-17v.

${ }^{13}$ AHU. Pará (avulsos). Caixa 14, D. 1336. Há no ANTT apenas informaçôes sobre um homônimo, desembargador da Relação e Casa do Porto no final do século XVII. Chancelaria de D. Pedro II. Livro 18, fl. 267.
} 
soldos desde o embarque para a América, como de praxe, apresentou-se como "um soldado pobre com mulher e filho nesta Corte a quem está assistindo". ${ }^{14}$

\section{A seleção dos capitães-mores do Pará (1707-1737)}

Algumas conclusóes sobre os perfis e experiências dos capitães-mores como servidores régios foram tiradas a partir da caracterização das suas trajetórias. A ausência de símbolos de distinção social, como os hábitos das ordens militares, dificultou o acesso a dados biográficos. Por volta de 1712, José Velho de Azevedo chegou a fazer requerimento de um hábito da Ordem de Cristo, fundamentado em seu rol de serviços, mas no curso das pesquisas não foi encontrado processo de habilitação ou registro na chancelaria da Ordem atestando que o pretendente recebeu a mercê e cumpriu os rituais de admissão. ${ }^{15}$ Manuel de Madureira Lobo, ao que tudo indica, foi o único a ter sua nobreza publicamente reconhecida por meio do foro de escudeiro fidalgo, acrescentado do foro de cavaleiro fidalgo da Casa Real, no tempo em que era militar em Portugal. ${ }^{16}$

Não há, até o momento, elementos suficientes para delinear um perfil social acabado dos capitães-mores do Pará. Por outro lado, alguns traços conferiram certa uniformidade às trajetórias dos que governaram entre 1707 e 1737. A formação e os feitos militares destacaram-se como os principais atributos, sendo importante sublinhar a ocupação de postos no Estado do Maranhão, especialmente no Pará, como o de sargento-mor; em particular os conhecimentos técnicos e práticos de José Velho de Azevedo sobre a arte da fortificação; a atuação de quase todos na Guerra da Sucessão Espanhola, à semelhança do que Rafael Ale Rocha verificou nas trajetórias de titulares do governo e de ocupantes de postos militares no Estado do Maranhão, no século XVII, que lutaram contra os holandeses no Estado do Brasil, nas Guerras da Restauração de Portugal e em outras campanhas europeias. ${ }^{17}$

O exercício interino da governança, o desempenho de cargos na administração do Estado do Maranhão e a participação ativa na resolução de problemas locais também foram ressaltados na indicação de alguns componentes da amostragem. A leitura das patentes permitiu, ainda, mapear seus deslocamentos — associados ao ofício das armas — por diferentes territórios ultramarinos, como Angola e o Estado do Brasil. Essa circulação possibilitou a formação de um cabedal de experiências úteis à governança ${ }^{18}$ - José Velho de Azevedo e

\footnotetext{
${ }^{14}$ AHU. Pará (avulsos). Caixa 16, D. 1452.

${ }^{15}$ AHU. Pará (avulsos). Caixa 6, D. 491.

${ }^{16}$ ANTT. Registro Geral de Mercês. D. João V. Livro 5, fl. 16. Alvará de 8 de março de 1711.

${ }^{17}$ ROCHA, Rafael Ale. A elite militar no Estado do Maranhão: poder, hierarquia e comunidades indígenas (século XVII). Tese (doutorado em História Social) — Programa de Pós-graduação em História Social, Universidade Federal Fluminense, Niterói, 2013, p. 43-52.

${ }^{18}$ Sobre o "acúmulo de experiências" resultante da circulação de agentes pelos domínios ultramarinos, ver FRAGOSO, João; GOUVÊA, Maria de Fátima Silva; BICALHO, Maria Fernanda Baptista. Uma leitura do Brasil colonial: bases da materialidade e da governabilidade no Império. Penélope, Lisboa, n. 23, p. 79-83, 2000.
} 
Antônio Marreiros, por exemplo, participaram da mesma concorrência ao cargo de governador e capitão-general do Estado do Maranhão, o primeiro antes e o segundo depois de ser capitão-mor do Pará. ${ }^{19}$

As consultas do Conselho Ultramarino reforçaram certos juízos acerca da seleção dos capitães-mores, com base na extensão e no valor das açôes individuais, mesmo quando a decisão do rei não correspondeu ao escrutínio dos conselheiros. Pedro Mendes Tomás, por exemplo, recebeu a nomeação régia malgrado a terceira colocação na votação dos conselheiros, depois de José Pinheiro da Câmara — preferido por possuir "o foro de fidalgo e haver sido ferido de uma bala", embora tivesse o menor tempo de serviço, — e de Domingos de Matos Leitão. ${ }^{20}$ João de Barros da Guerra, por sua vez, teve a primazia em uma concorrência, da qual José Velho de Azevedo também participou, tendo os conselheiros emitido as seguintes consideraçóes:

[...] é muito conveniente que nas praças das conquistas se achem providos os postos em pessoas de todo o valor, e com toda a luz da disciplina e regra militar, temendo-se justamente que possam ser invadidas pelos inimigos desta Coroa, o que se não pode encontrar nos que estão servindo nelas por não haverem tido a experiência dos perigos dos que viram a guerra das nações da Europa. ${ }^{21}$

Diante da conjuntura da Guerra da Sucessão Espanhola, que viria a ter desdobramentos na América, ${ }^{22}$ o Conselho Ultramarino julgou conveniente escolher um capitão-mor experimentado em combates na Europa, como de resto se verificou em quase todos os sucessores de João de Barros da Guerra.

José Velho de Azevedo, Manuel de Madureira Lobo e Antônio Marreiros também tiveram a primazia em suas respectivas concorrências, tendo os conselheiros levado em conta a extensão, o valor dos serviços e as despesas feitas por José Velho para socorrer o governo do Estado do Maranhão e o tirocínio adquirido por Manuel de Madureira Lobo e Antônio Marreiros na Guerra da Sucessão Espanhola. À essa altura, a questão da fronteira entre os domínios franceses e portugueses já era motivo de preocupação para quem governava o Pará. $^{23}$

Não bastasse o silêncio sobre os feitos de Antônio Duarte de Barros, verificou-se que ele não participou da concorrência da qual saiu nomeado por despacho régio. Surpreende,

\footnotetext{
${ }^{19}$ AHU. Consultas mistas. Códice 22, fl. 141v-142.

${ }^{20}$ AHU. Consultas mistas. Códice 20, fl. 63-65.

${ }^{21}$ AHU. Consultas mistas. Códice 20, fl. 226-226v.

${ }^{22}$ Para essa questão, ver RODRIGUES, José Damião. O império territorial. In: COSTA, João Paulo Oliveira e (Coord.). História da expansão e do império português. Lisboa: A Esfera dos Livros, 2014, p. 237-241.

${ }^{23}$ AHU. Consultas mistas. Códice 21, fl. 80-81 (José Velho de Azevedo) e fl. 332v-333 (Manuel de Madureira Lobo). Códice 22, fl. 223-224v (Antônio Marreiros).
} 
ainda, o fato de o cargo ter sido disputado por oito candidatos (três aparentemente não apresentaram seus papéis, sendo apenas citados como pretendentes), o maior número de concorrentes desde a nomeaçáo de Pedro Mendes Tomás. Pelo menos um postulante havia lutado na Guerra da Sucessão Espanhola e outro, Diogo Rodrigues Pereira, tinha quase 30 anos de serviços no Estado do Maranhão e nas capitanias da Bahia e de Pernambuco. ${ }^{24}$

Não há dados que permitam inferir sobre a preferência por Antônio Duarte de Barros ou por Pedro Mendes Tomás, diferentemente dos casos em que houve concordância da Coroa com as consultas do Conselho Ultramarino, por ser a amostragem demasiadamente reduzida para sustentar conclusôes mais gerais. Situação análoga foi percebida por Mafalda Soares da Cunha, posto que em uma investigação de maior alcance e centrada em outra temporalidade sobre a seleção de administradores coloniais. ${ }^{25}$ A partir da década de 1720, após a Guerra da Sucessão Espanhola, segundo Nuno Monteiro, houve um aumento das nomeaçóes de governantes pelo monarca em desacordo com as decisóes do Conselho Ultramarino. ${ }^{26}$

\section{O governo do Pará na primeira metade do século XVIII: aspectos gerais}

Para solucionar dúvidas e pôr fim aos problemas decorrentes da falta de um instrumento "por onde se governassem os capitáes-mores", o príncipe regente D. Pedro ordenou a elaboração de um regimento. ${ }^{27} \mathrm{O}$ primeiro dos 29 capítulos versava sobre os ritos de posse. Caso o capitão-mor fosse diretamente para Belém, devia avisar "ao governador de como sois chegado e lhe enviareis a minha carta e a de crença que levais ao capitão-mor a quem ides suceder, pela qual vos há de fazer entrega daquela capitania, havendo-lhe por levantado o preito e homenagem que me fez". ${ }^{28}$

O preito e homenagem era fundamental nos protocolos de investidura. Segundo Francisco Cosentino, na cerimônia do preito \& menagem, de origem medieval, aqueles designados para exercer algum poder delegado pelo rei (regalia), no reino ou nos domínios ultramarinos, prestavam o juramento de fidelidade ao monarca. Os administradores coloniais (vice-reis, governadores-gerais ou governadores de capitania) faziam-no antes de partir, como

\footnotetext{
${ }^{24}$ AHU. Consultas mistas. Códice 23, f1. 26-27v.

${ }^{25}$ CUNHA, Mafalda Soares da. Governo e governantes do império português do Atlântico (século XVII). In: BICALHO, Maria Fernanda; FERLINI, Vera Lúcia Amaral (Org.). Modos de governar: ideias e práticas políticas no império português (séculos XVI a XIX). São Paulo: Alameda, 2005, p. 72-75.

${ }^{26}$ MONTEIRO, Nuno Gonçalo. Governadores e capitáes-mores do império atlântico português no século XVIII. In: BICALHO, Maria Fernanda; FERLINI, Vera Lúcia Amaral (Org.). Modos de governar: ideias e práticas políticas no império português (séculos XVI a XIX). São Paulo: Alameda, 2005, p. 100-102.

${ }^{27}$ Arquivo da Universidade de Coimbra (doravante AUC). Coleção Condes de Arcos (Pará). VI-III-1-1-30. Livro de Regimentos do Estado de Maranhão e Pará, 1688-1774. O Regimento, de 5 de junho de 1669, atendeu a uma representação do capitão-mor Marçal Nunes da Costa (1658-1662 e 1674-1685).

${ }^{28}$ Ibidem, [fl. 1].
} 
previam suas patentes. $\mathrm{O}$ ritual "concedia consistência e legitimidade às práticas delegativas de poder, como era a nomeação de alguns governantes das conquistas ultramarinas". ${ }^{29}$ No Estado do Maranhão fez-se presente no discurso de capitães-mores, consoante o seu entendimento — ou conveniência — em disputas jurisdicionais entre oficiais régios, ou ainda em função de eventuais animosidades entre o capitão-mor do Pará e o governador e capitão-general do estado.

Alguns exemplos ilustram essas possibilidades. Em carta ao rei, de 25 de julho de 1714, João de Barros da Guerra questionou o fato de o ouvidor e provedor da Fazenda não acatar suas ordens para tirar devassas e mandar apurar descaminhos, quando o governador e capitão-general estivesse em São Luís. Considerou essa postura

[...] contrária ao estilo observado nesta capitania por se não poder recorrer com prontidão ao governador, [...] pela distância e dilação de três meses ao menos; assim para a expedição das ordens, como porque os capitáes maiores desta capitania são governadores dela, por patente de Vossa Majestade, de que dão preito e homenagem. ${ }^{30}$

A contrariedade de João de Barros da Guerra sinalizava para a discrepância entre as disposiçóes do Regimento dos Capitães-mores do Pará e a realidade da administração, pois o capítulo 7 estabelecia: "em nenhuma forma vos intrometais na administração da Fazenda Real dessa capitania; pois toca somente ao provedor dela: mais tereis particular cuidado que se aumente, e havendo algum descaminho, dareis conta ao governador do Estado, e a mim também”. A mesma liberdade era estendida aos oficiais da Justiça (capítulo 8). ${ }^{31}$

Em 1723, Manuel de Madureira Lobo foi repreendido pelo rei depois de o governador e capitão-general João da Maia da Gama enviar queixa a Lisboa, alegando que o capitão-mor teria se valido do equívoco cometido por um oficial ao atestar no verso de sua carta patente que ele havia prestado homenagem como "governador" do Pará. Diante disso, Manuel de Madureira Lobo teria arrogado a si prerrogativas incompatíveis com o cargo de capitão-mor que efetivamente exercia, como o direito de ser tratado por "senhoria" e de ocupar lugar diferente de seus antecessores, por exemplo, na festividade de Santo Inácio, quando mandou "pôr um tamborete com um coxim no arco defronte do governador" do estado. ${ }^{32} \mathrm{O}$ capítulo 26 estabelecia que na assistência do capitão-general em Belém, o capitão-mor, seu subordinado (capítulo 4), prestar-lhe-ia "as honras devidas, como a vosso

\footnotetext{
${ }^{29}$ COSENTINO, Francisco Carlos. Governadores Gerais do Estado do Brasil (séculos XVI-XVII): ofício, regimentos, governação e trajetórias. São Paulo: Annablume/Fapemig, 2009, p. 85-101. Conferir citação à página 88. ${ }^{30}$ AHU. Pará (avulsos). Caixa 6, D. 505.

${ }^{31}$ AUC. Coleção Condes de Arcos (Pará). VI-III-1-1-30. Livro de Regimentos do Estado de Maranhão e Pará, 1688-1774, s/n.

${ }^{32}$ AHU. Códice 269, fl. 233-233v.
} 
governador e nos atos públicos em que se achar, tereis vosso assento devido abaixo dele à sua mão direita".33

Além das questôes de precedência e das querelas em torno de atribuiçôes de oficiais régios, é preciso atentar para as linhas gerais da ação governativa dos capitães-mores, especialmente quanto à defesa, ao trato com os índios, ao fomento da produção e à busca de minas. Os capítulos iniciais do regimento explicitaram as atribuiçôes militares do capitão-mor do Pará. Cabia-lhe, depois de empossado, avaliar o estado das fortificaçóes, identificar os reparos necessários, inspecionar os armazéns de artilharia, a fim de levantar a quantidade de armas e de muniçôes disponíveis, informando tudo ao governador e capitão-general e ao rei (capítulo 2). Em seguida, competia-lhe levantar o quantitativo da gente disponível para a guerra, convocando-a duas vezes por ano e discriminando os contingentes e seus armamentos em listas enviadas ao governador do estado e ao rei (capítulo 3).

É possível concluir que o capitão-mor mantinha funções primordiais de defesa, tal como no início da ocupação do norte amazônico e na época da fundação do Estado do Maranhão (1621), quando a conquista do território (dirigida pelo capitáo-mor) era mais premente que a colonização. ${ }^{34}$ António de Saldanha afirmou, a propósito da doação da capitania de Machico (1440), que "as funçôes governativas dos capitães" eram, em resumo: "administrar os povos em tempos de paz e de guerra, ministrando a justiça tornada indispensável à regência das sociedades humanas". 35

Os governos de Pedro Mendes Tomás, de João de Barros da Guerra e de José Velho de Azevedo corresponderam ao desenrolar da Guerra da Sucessão Espanhola, em que Portugal e França estavam em lados opostos. Durante o conflito na Europa, precauçôes foram tomadas para afastar ou combater os franceses. Em 8 de julho de 1708, Pedro Mendes Tomás deu conta a Lisboa da ameaça, que não se concretizou, de um ataque de 20 embarcaçóes francesas oriundas de Caiena a canoas de Sua Majestade. Em razão disso, reforçou as defesas da capitania com o apoio de índios da aldeia de Mortigura. ${ }^{36}$ Outra notícia de que uma frota de guerra partira da França em direção a América circulou dois anos depois e levou João de Barros da Guerra a erguer um "baluarte junto ao Convento de Santo Antônio" e a mobilizar a tropa paga e as ordenanças (incluindo a Companhia da Nobreza, por se tratar de uma situação de guerra) para guarnecer a cidade de Belém. ${ }^{37}$

\footnotetext{
${ }^{33}$ AUC. Coleção Condes de Arcos (Pará). VI-III-1-1-30. Livro de Regimentos do Estado de Maranhão e Pará, 1688-1774, s/n.

${ }^{34}$ Cf. WEHLING, Maria José Mesquita Cavalleiro de Macedo. O Estado do Maranhão na União Ibérica. Revista do Instituto Histórico e Geográfico Brasileiro, Rio de Janeiro, v. 166, n. 426, p. 59-66, jan./mar. 2005. ${ }^{35}$ SALDANHA, António Vasconcelos de. As capitanias do Brasil: antecedentes, desenvolvimento e extinçáo de um fenômeno atlântico. Lisboa: Comissão Nacional para as Comemoraçôes dos Descobrimentos Portugueses, 2001, p. 142.

${ }^{36}$ AHU. Códice 268, fl. 249.

${ }^{37}$ AHU. Códice 268, fl. 273-274v.
} 
O Tratado de Utrecht (1713) reconheceu os direitos de Portugal sobre as terras entre os rios Amazonas e Oiapoque. Mas não pôs fim aos problemas na fronteira do Pará com a Guiana Francesa, os quais demandavam permanentemente a atenção das autoridades coloniais e do Conselho Ultramarino, como o comércio ilícito entre índios dos domínios portugueses e os franceses e as fugas de escravos. ${ }^{38}$ Diante desse quadro, em 1716, o capitão-mor José Velho de Azevedo informou ao secretário de Estado Mendo de Fóios Pereira sobre a escassez de muniçôes e de soldados nas fortificaçôes. ${ }^{39}$ Mas a premência de reorganizar o sistema defensivo esbarrava em dissençóes com o provedor da Fazenda, o que já acontecia antes de José Velho assumir. Pela carta régia de 5 de abril de 1715, o rei determinara que as despesas com as "coisas de guerra" deviam ser feitas por resolução do capitâo-mor, por serem de sua alçada os assuntos militares, e enviadas ao provedor da Fazenda. Francisco Galvão da Fonseca, provedor no Pará, era acusado de duvidar dessa prerrogativa e de comprometer, com isso, o municiamento da tropa, os treinamentos de artilharia e mesmo as salvas nas festas e nas ocasiōes em que o governador e capitão-general chegava e partia de Belém. ${ }^{40}$

Nos anos que se seguiram, a correspondência oficial deu conta da persistência da escassez de efetivos militares e das ameaças francesas. Como em uma representaçáo de 1728, em que o governador e capitão-general Alexandre de Sousa Freire, que estava no Pará (quando Antônio Marreiros era o capitão-mor), denunciou a grande redução da tropa — dos cerca de 250 que formavam as cinco companhias de infantaria restariam apenas 27. Por isso, temia ainda mais conflitos na fronteira com Caiena. Relatou também que do efetivo de 70 soldados que o acompanharam na jornada a Belém, tinha "já fugido a maior parte dele por irem pela ocasião e cobiça das minas de ouro". ${ }^{41}$

Como se vê, a (in)disponibilidade de contingentes militares aparecia algumas vezes atrelada a outras questóes da administração local, cujo aprofundamento excederia os limites deste artigo, como a busca de minas, além dos descimentos e dos resgates de índios no sertáo, que demandavam a participação de soldados. Pedro Mendes Tomás esteve envolvido nesses resgates $^{42}$ e João de Barros da Guerra teria desfalcado as fortificaçóes do Pará ao se oferecer para comandar uma expedição contra os índios do Rio Madeira, "pelos grandes danos que nos

\footnotetext{
${ }^{38}$ Cf. GOMES, Flávio dos Santos. Fronteiras e mocambos: o protesto negro na Guiana Brasileira. In: (Org.). Nas terras do Cabo Norte: fronteiras, colonização e escravidão na Guiana Brasileira — séculos XVIII/ XIX. Belém: Ed. Universitária UFPA, 1999, p. 226-227. Uma discussão recente sobre a questão da fronteira entre o Pará e o Cabo do Norte, enfocando a ocupação indígena da regiáo, a importância dos conhecimentos cartográficos para a definição de limites e os conflitos diplomáticos entre Portugal e França pode ser encontrada em CHAMBOULEYRON, Rafael e BARARUÁ, Marcus Vinícius Valente. Cabo do Norte: conflitos e territorialidade (XVII-XVIII). Revista Estudos Amazônicos. Belém, v. X, n. 1, p. 255-278, 2014.

${ }^{39}$ AHU. Pará (avulsos). Caixa 6, D. 523.

${ }^{40}$ AHU. Pará (avulsos). Caixa 6, D. 560.

${ }^{41}$ AHU. Códice 209, fl. 32v.

${ }^{42}$ Para a questáo dos descimentos e das tropas de resgate ver, por exemplo, MELLO, Márcia Eliane Alves de Souza e. Fé e império: as juntas das missōes nas conquistas portuguesas. Manaus: Edufam, 2009, p. 247-295.
} 
tinham feito impedindo com as suas hostilidades a que os missionários fizessem o serviço de Deus". Acabou morrendo quando "lhe caíra um pau sobre a canoa" em que viajava de volta ao rio Madeira, depois de se restabelecer em Belém de uma moléstia contraída no sertão. ${ }^{43}$

O envolvimento de José Velho de Azevedo, na condição de senhor de engenho, no trato com os índios, foi identificado em meio aos requerimentos de particulares para a realização de descimentos, a exemplo do que fez Jerônimo Vaz Vieira, em sociedade com o antigo capitáo-mor e outros dois interessados, em 1725. Por causa da morte de mais de 50 índios em uma epidemia e da falta de escravos negros no Estado do Maranhão, pretendia descer 50 casais e empregar sua parte em um engenho real de açúcar e noutro de aguardente. ${ }^{44}$

O capítulo 6 do Regimento dos Capitães-mores do Pará ordenava o apoio e o favorecimento dos missionários em seu trabalho de expansão da fé, enquanto os capítulos 14 e 15 versavam sobre o modo de se fazer os resgates e as entradas de particulares no sertão. ${ }^{45} \mathrm{Na}$ prática, contudo, tais disposições não dão conta do exame de todas as situaçôes em que a Lei, como o posterior Regimento das Missóes (1686) ou as decisóes régias complementares, não foi respeitada em função de interesses dos moradores ${ }^{46}$ ou de atos indevidos de gente da governança ${ }^{47}$ Como o praticado por Manuel de Madureira Lobo, que teria fornecido índias farinheiras e amas de leite a quem não precisava delas, contrariando o Regimento das Missóes e motivando a queixa do superior da Companhia de Jesus, padre José Vidigal. ${ }^{48}$ Esse exemplo aponta para o favorecimento de moradores e pode ser associado à participação do capitão-mor em um "motim” no Pará, provocado por dissençôes com os jesuítas e o governador João da Maia da Gama em torno da escravidão indígena. ${ }^{49}$

Foi também levantada a hipótese, com base em um requerimento enviado a Lisboa, de que Manuel de Madureira Lobo, recém-nomeado, cogitava tirar proveito do cargo. ${ }^{50}$

\footnotetext{
${ }^{43}$ AHU. Códice 269, fl. 73v. João de Barros da Guerra fez um testamento em 23 de abril de 1715, quando estava prestes a partir para o sertão. Infelizmente, o documento é omisso quanto às carregaçóes que o capitão-mor enviava para o reino e aos seus bens no Pará. ANTT. Registro Geral de Testamentos. Livro 147, fl. 14v-18. ${ }^{44}$ AHU. Pará (avulsos). Caixa 8, D. 739.

${ }^{45}$ AUC. Coleção Condes de Arcos (Pará). VI-III-1-1-30. Livro de Regimentos do Estado de Maranhão e Pará, 1688-1774, s/n.

${ }^{46}$ Cf. MELLO, Márcia Eliane Alves de Souza e. Fé e império: as juntas das missões nas conquistas portuguesas, op. cit., p. 249-295.

${ }^{47}$ Para essas situaçóes, cujo exame excede os limites deste artigo, ver MELLO, Márcia Eliane Alves de Souza e. Ibidem, p. 270ss.

${ }^{48}$ AHU. Pará (avulsos). Caixa 7, D. 606. Sobre os critérios para a repartição das índias farinheiras e amas de leite aos moradores, ver MELLO, Márcia Eliane Alves de Souza e. Ibidem, p. 249-250.

${ }^{49}$ Uma abordagem aprofundada das irregularidades no cativeiro indígena em que Manuel de Madureira Lobo se envolveu encontra-se em DIAS, Joel Santos. Os "verdadeiros conservadores" do Estado do Maranhão: poder local, redes de clientela e cultura política na Amazônia colonial (primeira metade do século XVIII). Dissertação (mestrado em História Social da Amazônia) — Programa de Pós-graduação em História Social da Amazônia, Universidade Federal do Pará, Belém, 2008, p. 103-125.

${ }^{50}$ AHU. Pará (avulsos). Caixa 6, D. 557. Nada foi comprovado até o momento, inclusive, por causa da prisão de Manuel de Madureira Lobo em razáo de contendas com o governador João da Maia da Gama em torno da repartição de índios.
} 
A propósito de bem servir ao rei, solicitou permissão para instalar no Pará uma fábrica de descascar arroz, com garantia de exclusividade no emprego da técnica e de liberdade para indicar quem desejasse utilizá-la no beneficiamento de outras produçóes locais. Propôs também a construção de um tipo de engenho para fabricar açúcar que não utilizasse água ou bestas para moer a cana. Obteve autorização para a instalação desse invento e para receber 200 contos de réis de uma vez ou cinco arrobas de açúcar daqueles que o utilizassem. Sobre o pedido feito na mesma ocasiáo para se lançar ao descobrimento de minas de ouro, prata e outros metais em terras de Sua Majestade ou de donatários, sem impedimento de terceiros, a Coroa se mostrou reticente.

O Conselho Ultramarino emitiu parecer favorável ao estabelecimento de uma fábrica de descascar arroz, por uma vida, mas não para a atividade mineradora. Foram autorizadas, contudo, diligências para averiguar se as minas estavam em terras lusas ou em domínios franceses, castelhanos ou holandeses. O capítulo 24 do Regimento dos Capitães-mores do Pará incentivava o descobrimento de minas de ouro e de prata, sobre as quais havia indícios. As ordens para localizá-las eram claras, não devendo o capitão-mor descuidar da "cultura do cravo, e anil, e cacau, e as mais drogas que nesse sertão houver". ${ }^{1}$

A conjuntura da primeira metade do século XVIII afigurou-se desaconselhável ao investimento na mineração na regiáo Norte. Em 1711, Cristóvão da Costa Freire suspendeu os descobrimentos no rio Tocantins, "pela notícia [...] de irem os franceses ao Rio de Janeiro e [...] também de haver minas no dito rio, o que podia convidar aos inimigos para esse estado". A Coroa aprovou a medida, mas ordenou que o governador e capitão-general fornecesse, debaixo de absoluto sigilo, coordenadas mais precisas da localização das minas, recorrendo a "pessoa que com toda a cautela as vá examinar e da riqueza delas buscando-se outro pretexto para esta averiguaçáo de tal maneira que se não perceba o fim a que se encaminha”. Ainda em 1711, em decorrência da invasão francesa ao Rio de Janeiro, o capitão-general foi autorizado a aplicar as sobras de dinheiro da Fazenda Real em obras de reconstruçáo e na recomposição da artilharia do Fortim de Nossa Senhora das Mercês e de outras fortificaçôes de Belém. ${ }^{52}$

Apesar dos escrúpulos, a descoberta de minas não foi abandonada. Assim, em 1722, o governador João da Maia da Gama foi instruído a investigar a existência delas nos domínios portugueses por haver notícia de que haviam sido encontradas na província de Quito, devendo averiguar a distância das eventuais reservas em relação aos domínios castelhanos, franceses e holandeses. Uma década mais tarde, no governo de Alexandre de Sousa Freire, o Conselho Ultramarino continuava recomendando cautela quanto ao negócio, ponderando sobre a fragilidade das defesas do Estado do Maranhão,

\footnotetext{
${ }^{51}$ AUC. Coleção Condes de Arcos (Pará). VI-III-1-1-30. Livro de Regimentos do Estado de Maranhão e Pará, 1688-1774, s/n.

${ }^{52}$ AHU. Códice 268, fl. 273v e 275v.
} 
[...] entre todos os domínios que a Real Coroa de Vossa Majestade possui na América o menos bem defendido pela falta de habitadores, e o mais exposto pelos confinantes; os espanhóis confinam, e tem comunicação com o Pará que é do mesmo governo; os holandeses de Suriname penetram o interior daquele país até o rio Napo que por aquela parte divide os domínios de Vossa Majestade dos de Espanha; e os franceses, senhores da vila de Caiena, buscam repetidamente pretextos para passarem aos nossos sertôes a fazer comércio. ${ }^{53}$

Indícios da descoberta de ouro poderiam atiçar principalmente os espanhóis e os franceses, aumentando de tal modo o contrabando, que o governo do Estado do Maranhão não teria forças para contê-lo. Os franceses, em especial, já manifestavam seus interesses confundindo os termos do Tratado de Utrecht. A existência e a exploração de minas poderiam justificar investidas desses contendores, levando-os a "afetar alguma pretensão [territorial] ou introduzir o seu comércio". Por isso, o Conselho Ultramarino desencorajava a atividade mineradora na regiáo, uma vez que "a economia do Estado e a conservação dele com atento e político exame das suas forças, não permite que se arrisque o muito que já temos pelo mais que desejamos ter". Além do mais, o investimento na prospecção de minas desorganizaria a produção agrícola e tornaria mais difícil o cumprimento das leis sobre a utilização do trabalho indígena.

Nesse sentido, a questão da exploração mineral no Estado do Maranhão pode estar na origem da provisão de 31 de maio de 1737, "determinando que a população do Estado do Maranhão se dedicasse apenas à agricultura, sem interferir na exploração das minas", ${ }^{54}$ uma vez que novas sobre achados auríferos se espalharam e teriam estimulado grande afluxo de pessoas para o Estado do Maranhão. Foi o que relatou - com possível exagero — o jesuíta João Batista Carbone, em carta enviada de Lisboa a um correspondente em Roma: "chegou a nossa frota do Maranhão e traz ouro das novas minas que se descobriram naquele estado, para onde concorreram logo mais de três mil brancos para minerarem com negros e com gente da terra" 55

\section{O governador e capitão-general em Belém}

A necessidade de rediscutir certos aspectos da estrutura e da dinâmica administrativa do Estado do Maranhão e Grão-Pará, mormente, a partir da segunda metade do século XVII, foi despertada por uma divergência historiográfica quanto à mudança da sua capital,

\footnotetext{
${ }^{53}$ AHU. Códice 209, fl. 56v-58. Essa referência abrange as citaçôes no parágrafo seguinte.

${ }^{54}$ Cf. SALGADO, Graça (Coord.). Fiscais e meirinhos: a administração no Brasil colonial. 2. ed., Rio de Janeiro: Nova Fronteira, 1985, p. 430.

${ }^{55}$ Biblioteca da Ajuda (doravante BA). 51-X-31, fl. 172-173. Carta de 4 de dezembro de 1736.
} 
para alguns ocorrida em 1737 e para outros em 1751. Essas interpretaçóes remontam, pelo menos, ao início do século XIX. Em 1808, o inglês Robert Southey afirmou que o governador e capitão-general Pedro César de Meneses (1671-1678) transferiu a sede do governo de São Luís para Belém, "sendo mais favoravelmente situada esta cidade tanto para reunir os produtos naturais do país quanto para prosseguir na descoberta do sertão" ${ }^{56}$ Nos anos de 1830, o sargento-mor Antônio Ladislau Monteiro Baena esclareceu diversos pontos acerca da estrutura e da dinâmica administrativa do Estado do Maranhão:

A cidade de São Luís era a residência habitual dos encarregados do Governo Geral do Maranhão e Pará: eles depois de receber o bastão vinham à cidade de Belém, onde igualmente eram investidos da autoridade superior, e se demoravam enquanto as circunstâncias do tempo inculcassem e precisão de não partir senão quando por falta de negócios desordinários [sic] fossem levados a praticar a tornada para a cidade do Maranhão. ${ }^{57}$

Em seguida, Baena assinalou que "na ausência do governador e capitáo-general substituía-o na administração pública o capitão-mor da cidade [de Belém], em que o mesmo não assistia”. Por fim, o militar português fez um sumário das mudanças da sede do governo do Estado do Maranhão, desde o ano de 1673, quando "transferiu o governador e capitão-general Pedro César de Meneses a sua residência do Maranhão para a cidade de Belém, onde a continuaram os seus sucessores, menos Gomes Freire de Andrade" ${ }^{58}$

Inácio Coelho da Silva (1678-1682) recebeu ordens para se instalar em Belém. A carta régia de $1^{\circ}$ de dezembro de 1677 determinou aos oficiais da Câmara do Maranhão que tão logo dessem posse ao governador e capitão-general ele deveria se dirigir à capitania subalterna e, posteriormente, informar à Coroa "das conveniências que há de se passar o governo desse Estado ao Pará" 59

A medida foi alvo de questionamentos do governador recém-nomeado. Em uma representação, Inácio Coelho da Silva expôs os principais motivos para sua assistência na capitania do Pará: $1^{\circ}$ - continuar as obras de fortificação iniciadas por seu antecessor, Pedro César de Meneses; $2^{\circ}$ - instalar os casais de ilhéus que chegavam e os que viriam, a fim de povoar "aquelas terras, por serem firmes e muito dilatadas, capazes de toda a agricultura", especialmente as culturas do cacau e da baunilha. ${ }^{60}$ Mas atentou para possíveis desconten-

${ }^{56}$ SOUTHEY, Robert. História do Brasil. Trad. Luís Joaquim de Oliveira e Castro. Belo Horizonte: Itatiaia; São Paulo: EdUsp, 1981, v. 2, p. 342.

${ }^{57}$ BAENA, Antônio Ladislau Monteiro. Ensaio corográfico sobre a província do Pará. Brasília: Ediçóes do Senado Federal, 2004, p. 113.

${ }^{58} \mathrm{Idem}$. Ver também BA. 54-XI-27, n. 17, fl. 10v - Memória das pessoas que desde o princípio da conquista governaram as duas capitanias, do Maranhão e Grão-Pará (1783).

${ }^{59}$ AHU. Códice 268, fl. 19v-20 e 22v.

${ }^{60}$ AHU. Pará (avulsos). Caixa 5, D. 621. Sobre o povoamento do Estado do Maranhão por populaçôes das ilhas do Atlântico, entre a segunda metade do século XVII e o início do século XVIII, ver CHAMBOU- 
tamentos dos moradores e dos camaristas de São Luís e, por isso, sugeriu assistir — no primeiro ano de governo - seis meses em São Luís e outros seis em Belém, a fim de conhecer a realidade de sua jurisdição. ${ }^{61}$

A decisão de "alterar por ora a assistência do governador do Maranhão na cidade de São Luís e passar ao Pará e fazer ali cabeça do governo”, além de provisória, não alteraria a resolução régia de 13 de agosto de 1650, pela qual "os governadores façam sua assistência no Maranhão e não passem ao Pará”. O conselheiro Feliciano Dourado propôs que Inácio Coelho da Silva se guiasse pelo capítulo 19 do Regimento de André Vidal de Negreiros (1655) e partisse munido de uma carta "em que Vossa Alteza lhe ordene que vá assistir no Pará, enquanto se póem com efeito a cultura do cacau e baunilhas para que tudo se execute com bom sucesso, e acabada a forma daquela cultura, se tornará para o Maranhão”. Isso era necessário, pois, segundo o parecer do conselheiro, "sem a assistência ordinária dos governadores no Maranhão se arrisca aquele estado a uma grande ruína”. ${ }^{62}$

Na primeira metade do século XVIII, a frequência dos governadores e capitães-generais em Belém consolidou-se como um traço da dinâmica administrativa do Estado do Maranháo. Na carta patente de João da Maia da Gama (1722-1728), por exemplo, consta que receberia o soldo de seis mil cruzados como governador e capitão-general e mais mil cruzados "em cada um dos que com efeito passar ao Pará e tornar para o Maranhão". ${ }^{63}$ No decorrer do período, dada a permanência dos governadores e capitães-generais no cargo por mais de um triênio e a sua prolongada estadia em Belém, a figura do capitão-mor do Pará teve suas funçôes governativas cada vez mais reduzidas, restringindo-se ao plano militar.

Quando o governador do Estado do Maranhão se ausentava de São Luís, seu lugar era ocupado interinamente pelo capitão-mor do Maranhão. Diferenças de precedência não passavam despercebidas, tanto na cabeça do Estado quanto na capitania subalterna. Um exemplo foi a solicitação do capitão-mor do Pará, Antônio Marreiros, para que seu soldo fosse elevado de 200 para 400 mil réis anuais, alegando que o capitão-mor do Maranhão, que exercia função essencialmente militar e esporadicamente de governo, já havia recebido o aumento. ${ }^{64}$

Em caso de vacância ou de morte do governador e capitão-general era o capitão-mor quem assumia seu lugar interinamente. Em razão do falecimento de José da Serra, em Belém, Antônio Duarte de Barros o substituiu por cerca de um ano. Sua má fama levou

LEYRON, Rafael. A Amazônia colonial e as ilhas atlânticas. Canoa do Tempo, Manaus, v. 2, n. 1, p. 187-204, jan./dez. 2008.

${ }^{61}$ AHU. Pará (avulsos). Caixa 5, D. 621.

${ }^{62}$ AHU. Pará (avulsos). Caixa 5, D. 621. O capítulo 19 do Regimento de André Vidal de Negreiros (1655) dizia que o Pará "se tem por conquista de grandes esperanças assim pala grandeza da capitania como pela bondade das terras, e comodidades para engenho de açúcar de açúcar, e criaçôes de gado vacum, e que tem grandes matas de árvores de cravo, e noz moscada como a da Índia”. AHU. Códice 1107, fl. 9v-10.

${ }^{63}$ ANTT. Chancelaria de D. João V. Livro 62, fl. 24v. Carta patente de 28 de março de 1722.

${ }^{64}$ ANTT. Chancelaria de D. João V. Livro 74, fl. 114-115. 
o secretário de governo a deliberar com a Câmara que ele "governasse o militar somente, independente do político e econômico, por ser notória a incapacidade que em ele existia para expedição de negócios e dependências de qualquer operação do governo político”, ficando todos esses assuntos sob a alçada da Câmara. ${ }^{65}$

Antônio Duarte de Barros despontou como um governante atrabiliário, conforme a documentação consultada. Não faltaram reclamaçóes dos oficiais da Fazenda e da Justiça de falta de apoio militar para suas diligências, de revogação de patentes e nomeaçóes feitas pelo governador falecido, e de má conduta, como navegar com um filho pelo rio Guamá pedindo esmolas a título de missas e auferindo cacau e outros gêneros dos moradores. Em relação ao provedor da Fazenda as acusaçóes eram recíprocas. Enquanto o capitão-mor afirmava cumprir suas funçóes, inspecionando as fortalezas dos Pauxis e dos rios Negro e Tapajós, acusava Matias da Costa e Sousa de pôr obstáculos ao fornecimento de índios para tais obras e de cuidar "mais nos seus particulares interesses" no tocante à arrematação dos dízimos. ${ }^{66}$

Por ter sido nomeado no mesmo ano em que José da Serra - que passou boa parte do seu mandato em Belém — foi alçado ao governo do Estado do Maranhão (1732), Antônio Duarte de Barros não aparece nas fontes como responsável direto pelo governo do Pará. E seu tempo à frente da capitania praticamente coincidiu com os quatro anos de José da Serra na administração do Estado. Esse dado chama atenção não apenas para os efeitos da assistência do governador e capitão-general em Belém sobre a autoridade do capitão-mor do Pará, mas também para a continuidade do exercício dessa função a partir de 1737, uma vez que João de Abreu Castelo Branco (1737-1747) e Francisco Pedro de Mendonça Gorjão (17471751) já foram empossados naquela cidade. ${ }^{67}$

A posição da capital do Pará como a sede administrativa do Estado do Maranhão foi construída paulatinamente desde o século XVII. Arthur Cezar Ferreira Reis resumiu as qualidades de Belém na primeira metade do século XVIII. Para o historiador, a cidade oferecia melhores condições para o enfrentamento dos problemas de fronteira com a Guiana Francesa e o vice-reino do Peru e tinha uma população bem provida de meios e prestigiada desde as campanhas contra os holandeses. ${ }^{68}$ Arno e Maria José Wehling enfatizaram o crescimento econômico da urbe, amparado na escravidão indígena e no comércio das drogas do sertão, e afirmaram: "em 1737, dada a importância de Belém, para ela foi transferida a sede do Estado do Maranhão". ${ }^{69}$ De fato, por volta de 1737/1738, a agenda dos governadores e capitães-generais continha entendimentos sobre limites entre Quito e o Pará ou negativas de avanços

\footnotetext{
${ }^{65}$ AHU. Pará (avulsos). Caixa 19, D. 1811.

${ }^{66}$ AHU. Pará (avulsos). Caixa 19, D. 1733; D. 1735; D. 1788; D. 1792; D. 1795 e D. 1811. Conferir citação na Caixa 19, D. 1779.

${ }^{67}$ BAENA, Antônio Ladislau Monteiro. Compêndio das eras da província do Pará, op. cit., p. 220 e 226.

${ }^{68}$ REIS, Arthur Cezar Ferreira. Estadistas portugueses na Amazônia. Rio de Janeiro: Ediçốes Dois Mundos, 1948 , p. 45.

${ }^{69}$ WEHLING, Arno; WEHLING, Maria José C. de. Formação do Brasil colonial. Rio de Janeiro: Ed. Nova Fronteira, 1994, p. 178.
} 
militares em direção a missôes jesuíticas em terras espanholas. Essas questôes perduraram nas décadas seguintes, sobretudo a partir de 1750 , com a assinatura do Tratado de Madri. ${ }^{70}$

Importa salientar, em primeiro lugar, que essa conjuntura ligada às tratativas sobre limites, ao comércio com possessôes estrangeiras, aos progressos materiais e à posição geográfica mais favorável da capital do Pará, de acordo com alguns autores, consagrou a interpretação de que a capital do Estado do Maranhão foi transferida para Belém em 1737. Essa versão aponta para um processo - ainda não contemplado em toda a sua dimensão pela historiografia - de construção da capitalidade da urbe. Sem desconsiderá-lo, outros autores indicaram que a mudança da capital ocorreu, de fato, em 1751, quando foi oficializada pela Coroa nas Instruçôes a Francisco Xavier de Mendonça Furtado. ${ }^{71}$

Em segundo lugar, o processo de transferência da capital do Estado do Maranhão também se refletiu na nomeação de capitães-mores para a capitania do Pará. Em pelos menos duas obras consultadas, a lista se encerra em 1737 com Antônio Duarte de Barros. ${ }^{72}$ Isso pode ser explicado pela presença amiúde dos governadores e capitães-generais em Belém, responsável, na prática, pela extinção das funçôes governativas do capitão-mor. Embora não haja menção em Baena ou em Varnhagen de nomeaçôes posteriores a 1737, elas continuaram sendo feitas, admitindo-se, entretanto, que os capitáes-mores tenham se restringido à atribuição militar inerente ao posto.

Para a sucessão de Antônio Duarte de Barros foram lançados editais, mas os quatro candidatos que apresentaram seus papéis ao Conselho Ultramarino foram recusados pelo rei. Damião de Bastos e João de Almeida da Mata possuíam largos serviços no Estado do Maranhão — o primeiro tinha sido capitão-mor do Maranháo e foi recomendado —, enquanto o escolhido pelos conselheiros, Domingos de Morais Navarro, foi militar em Pernambuco e capitâo-mor do Rio Grande do Norte (1728-1731). Por ordem régia, novos editais foram lançados ainda em 1737 e a seleção — confirmada por d. João V — recaiu em Antônio da Costa de Oliveira, que oferecera seus préstimos mais relevantes na Guerra da Sucessão Espanhola. ${ }^{73}$

A ausência deste governante nas listas de administradores coloniais do Pará dificultou a precisão de seu mandato, mas é certo que em 1744 outros quatro indivíduos se candidataram ao cargo. Novamente, o rei determinou: "ponham-se novos editais e se ordene ao

\footnotetext{
${ }^{70}$ FBN. Divisão de Manuscritos. 04, 2, 021, n. 015. Biblioteca Geral da Universidade de Coimbra. Reservados. Ms. 488, fl. 140-144v. FBN. Divisão de Manuscritos. II - 31, 18, 020.

${ }^{71}$ Cf. FLEIUSS, Max. História administrativa do Brasil. Rio de Janeiro: Imprensa Nacional, 1923, p. 37. ARAÚJO, Renata Malcher de. As cidades da Amazônia no século XVIII: Belém, Macapá e Mazagão. Porto: FAUP, 1998, p. 105-106. Sobre as Instruçôes Régias de 31/05/1751, em especial a introdução e o capítulo 37, ver MENDONÇA, Marcos Carneiro de (Coord.). A Amazônia na era pombalina. Correspondência inédita do governador e capitáo-general do Estado do Grão-Pará e Maranhão Francisco Xavier de Mendonça Furtado (17511759). São Paulo: Instituto Histórico e Geográfico Brasileiro, 1963, t. 1, p. 26-38.

${ }^{72}$ BAENA, Antônio Ladislau Monteiro. Compêndio das eras da provincia do Pará, op. cit., p. 219ss. VARNHAGEN, Francisco Adolfo de. História Geral do Brasil. Rio de Janeiro: E. \& H. Laemmert, 1857, t. 2, p. 457.

${ }^{73}$ AHU. Consultas mistas. Códice 23, fl. 181-182 e fl. 244-244v. ANTT. Registro Geral de Mercês. D. João V. Livro 28, fl. 443. Carta patente de 29 de maio de 1737.
} 
governador que informe dos sujeitos propostos, e dos mais que julgar capazes deste posto". Apresentaram-se Estevão de Faria Delgado (indicado), José Miguel Aires, João de Figueiredo Sotomaior e Tomás Ferreira da Câmara. ${ }^{74}$ Àquela altura, segundo Nuno Monteiro, declinava o sistema de consulta aos conselhos para a tomada de decisóes políticas e d. João $\mathrm{V}$ "foi-se sempre consultando com quem quis, recorrendo para o efeito a juntas e a diversos personagens", como Alexandre de Gusmão. ${ }^{75}$

$\mathrm{Na}$ escolha do capitão-mor do Pará, conforme despacho à referida consulta, o rei ordenou que o governador e capitão-general do Estado do Maranhão desse o seu parecer. João de Abreu Castelo Branco respondeu que não tinha informaçôes sobre Estevão de Faria Delgado e João de Figueiredo Sotomaior, mas sabia da boa conduta de José Miguel Aires e de Tomás Ferreira da Câmara, que serviam no Pará. Preferiu endossar a pretensão do sargento-mor João de Almeida da Mata, "em razão da antiguidade do seu serviço [...] ao que acresce o bom procedimento com que se houve na minha ausência em todos os anos que fui visitar as capitanias do Maranhão, em que ficou substituindo as vezes de capitão-mor do Pará". ${ }^{6}$

No ano seguinte, João de Almeida da Mata foi o escolhido pelos conselheiros do Conselho Ultramarino e teve sua indicação confirmada pelo rei. ${ }^{77}$ Ratificando que a autoridade do governador do Estado do Maranhão assistente em Belém se sobrepunha à do capitão-mor do Pará, as atuaçôes de Antônio da Costa de Oliveira e de João de Almeida da Mata não são notadas, ao menos na documentação portuguesa, ao contrário de seus antecessores que governaram até 1737 .

\section{Considerações finais}

Este artigo representou um esforço inicial no sentido de construir as trajetórias de seis capitães-mores do Pará. O pequeno grupo, portanto, náo poderia dar ensejo a uma configuração geral do perfil dos governantes da capitania. Por outro lado, ainda haveria o que dizer dos indivíduos aqui privilegiados. Tinham interesses locais enraizados. Eram

\footnotetext{
${ }^{74}$ AHU. Consultas mistas. Códice 24, fl. 140-141.

${ }^{75}$ MONTEIRO, Nuno. As reformas na monarquia pluricontinental portuguesa: de Pombal a dom Rodrigo de Sousa Coutinho. In: FRAGOSO, João; GOUVÊA, Maria de Fátima (Org.). O Brasil colonial (17201821). Rio de Janeiro: Civilização Brasileira, 2014, v. 3, p. 116-117.

${ }^{76}$ AHU. Pará (avulsos). Caixa 27, D. 2562. Também contaram a favor de João de Almeida da Mata as "feridas que recebeu". Sobre a importância dos ferimentos de guerra nos requerimentos e nas tabelas remuneratórias de mercês, ver OLIVAL, Fernanda. As ordens militares e o Estado Moderno: honra, mercê e venalidade em Portugal (1641-1789). Lisboa: Estar, 2001, p. 138-145. Conferir p. 144.

77 AHU. Consultas mistas. Códice 24, fl. 186-188v. ANTT. Registro Geral de Mercês. D. João V. Livro 21, fl. 300. Carta patente de 13 de julho de 1745. Uma transcriçấo do termo de homenagem prestada ao rei por João de Almeida da Mata, em 25 de outubro de 1745, encontra-se em AZEVEDO, João Lúcio de. Os jesuítas no Grão-Pará: suas missões e a colonização. Belém: Secult, 1999, p. 325.
} 
proprietários de terras, de engenhos, de escravos, roças e lavouras. Construíram redes que não foram abordadas por excederem os limites da discussão proposta e por existir uma produção acadêmica sobre os poderes locais no Pará, inclusive, em nível de pós-graduação. Essas redes e seus interesses podem ser identificados partindo-se, por exemplo, dos autos de residência dos capitáes-mores ou dos registros de sesmarias.

A ação administrativa dos governantes do Pará é certamente mais complexa do que o panorama exposto, mas poderá ser aprofundada em outra ocasião. Foram destacados apenas os aspectos gerais, diretamente relacionados com os termos do Regimento dos Capitães-mores do Pará, uma peça menos conhecida e explorada que o Regimento dos Governadores e Capitães-generais do Estado do Maranhão, mais conhecido como o Regimento de André Vidal de Negreiros (1655).

As consideraçóes sobre o governo foram sempre que possível articuladas à proposta do tópico seguinte: a dinâmica administrativa no Estado do Maranháo, com ênfase na observação do exercício da autoridade na capitania quando o governador e capitâo-general para lá se deslocava, deixando o centro original de poder da repartição (Sáo Luís). Para dar avançar nessa direção, não é suficiente apoiar-se em fontes portuguesas. É de vital importância consultar outra espécie de documentação sob a guarda do Arquivo Público do Estado do Pará (APEP) e do Arquivo Público do Estado do Maranhão (APEM). Assim, será possível identificar os meandros e percorrer os caminhos da comunicação política entre governadores e capitães-generais e capitães-mores, inclusive das donatarias privadas.

Esses percursos pela correspondência trocada pelos administradores coloniais na jurisdição do Estado do Maranhão propiciarão, por exemplo, a construção das relaçóes políticas e pessoais entre o governador e capitáo-general general do Estado e os capitáes-mores subalternos; suas alianças, animosidades e os reflexos disso na prática governativa. Por todas as razóes apontadas, este artigo é menos conclusivo que propositivo. Anuncia, entrementes, a intenção de investigar a estrutura e a dinâmica político-administrativa do Estado do Maranhão, desde a sua criação no início do século XVII até o século XIX.

\section{Referências bibliográficas}

ARAÚJO, Renata Malcher de. As cidades da Amazônia no século XVIII: Belém, Macapá e Mazagáo. Porto: Faup, 1998.

AZEVEDO, João Lúcio de. Os jesuitas no Grão-Pará: suas missões e a colonização. Belém: Secult, 1999.

BAENA, Antônio Ladislau Monteiro. Compêndio das eras da província do Pará. Belém: Tipografia de Santos \& Santos Menor, 1838.

. Ensaio corográfico sobre a provincia do Pará. Brasília: Ediçóes do Senado Federal, 2004. 
CAETANO, Joaquim Oliveira; SOROMENHO, Miguel Conceição (estudos); FERREIRA, Teresa A. S. Duarte; SILVA, Ana Cristina de Santana; MARTINS, Lígia de Azevedo (textos). A ciência do desenho: a ilustração na coleção de códices da Biblioteca Nacional. Lisboa: Biblioteca Nacional, 2001.

CHAMBOULEYRON, Rafael. A Amazônia colonial e as ilhas atlânticas. Canoa do Tempo, Manaus, v. 2, n. 1, p. 187-204, jan./dez. 2008.

CHAMBOULEYRON, Rafael; BARARUÁ, Marcus Vinícius Valente. Cabo do Norte: conflitos e territorialidade (XVII-XVIII). Revista Estudos Amazônicos, Belém, v. X, n. 1, p. 255-278, 2014.

CHARLE, Christophe. A prosopografia ou biografia coletiva: balanço e perspectivas. In: HEINZ, Flávio M. (Org.). Por outra história das elites. Rio de Janeiro: FGV, 2006, p. 41-53. COSENTINO, Francisco Carlos. Governadores gerais do Estado do Brasil (séculos XVI-XVII): ofício, regimentos, governação e trajetórias. São Paulo: Annablume/Fapemig, 2009.

CUNHA, Ana Paula Macedo. Engenhos e engenhocas: atividade açucareira no Estado do Maranhão e Grão-Pará (1706-1750). Dissertação (Mestrado em História Social da Amazônia) - Programa de Pós-graduação em História Social da Amazônia, Universidade Federal do Pará, Belém, 2009.

CUNHA, Mafalda Soares da. Governo e governantes do império português do Atlântico (século XVII). In: BICALHO, Maria Fernanda; FERLINI, Vera Lúcia Amaral (Org.). Modos de governar: ideias e práticas políticas no império português (séculos XVI a XIX). São Paulo: Alameda, 2005, p. 69-92.

DIAS, Joel Santos. Os “verdadeiros conservadores" do Estado do Maranhão: poder local, redes de clientela e cultura política na Amazônia colonial (primeira metade do século XVIII). Dissertação (Mestrado em História Social da Amazônia) — Programa de Pós-graduação em História Social da Amazônia, Universidade Federal do Pará, Belém, 2008.

FLEIUSS, Max. História administrativa do Brasil. Rio de Janeiro: Imprensa Nacional, 1923. FRAGOSO, João; GOUVÊA, Maria de Fátima Silva; BICALHO, Maria Fernanda Baptista. Uma leitura do Brasil colonial: bases da materialidade e da governabilidade no Império. Penélope, Lisboa, n. 23, p. 67-88, 2000.

GOMES, Flávio dos Santos. Fronteiras e mocambos: o protesto negro na Guiana Brasileira. In: GOMES, Flávio dos Santos (Org.). Nas terras do Cabo Norte: fronteiras, colonização e escravidão na Guiana Brasileira — séculos XVIII/XIX. Belém: Ed. Universitária UFPA, 1999, p. 225-318.

MELLO, Márcia Eliane Alves de Souza e. Fé e império: as juntas das missões nas conquistas portuguesas. Manaus: Edufam, 2009.

MONTEIRO, Nuno Gonçalo. Governadores e capitães-mores do império atlântico português no século XVIII. In: BICALHO, Maria Fernanda; FERLINI, Vera Lúcia Amaral 
(Org.). Modos de governar: ideias e práticas políticas no império português (séculos XVI a XIX). São Paulo: Alameda, 2005, p. 93-115.

MONTEIRO, Nuno. As reformas na monarquia pluricontinental portuguesa: de Pombal a dom Rodrigo de Sousa Coutinho. In: FRAGOSO, João; GOUVÊA, Maria de Fátima (Org.). O Brasil colonial (1720-1821). Rio de Janeiro: Civilização Brasileira, 2014, v. 3, p. 111-156.

OLIVAL, Fernanda. As ordens militares e o Estado Moderno: honra, mercê e venalidade em Portugal (1641-1789). Lisboa: Estar, 2001.

REIS, Arthur Cezar Ferreira. Estadistas portugueses na Amazônia. Rio de Janeiro: Ediçóes Dois Mundos, 1948.

ROCHA, Rafael Ale. A elite militar no Estado do Maranhão: poder, hierarquia e comunidades indígenas (século XVII). Tese (Doutorado em História Social) — Programa de Pós-graduação em História Social, Universidade Federal Fluminense, Niterói, 2013.

RODRIGUES, José Damião. O império territorial. In: COSTA, João Paulo Oliveira e (Coord.). História da expansão e do império português. Lisboa: A Esfera dos Livros, 2014, p. 201-339.

SALDANHA, António Vasconcelos de. Ascapitanias do Brasil: antecedentes, desenvolvimento e extinção de um fenômeno atlântico. Lisboa: Comissão Nacional para as Comemoraçôes dos Descobrimentos Portugueses, 2001.

SALGADO, Graça (Coord.). Fiscais e meirinhos: a administração no Brasil colonial. 2. ed., Rio de Janeiro: Nova Fronteira, 1985.

SOUTHEY, Robert. História do Brasil. Trad. Luís Joaquim de Oliveira e Castro. Belo Horizonte: Itatiaia; São Paulo: EdUsp, 1981, v. 2.

STONE, Lawrence. Prosopography. The Past \& Present. Boston/Londres, p. 45-73, 1981.

VARNHAGEN, Francisco Adolfo de. História Geral do Brasil. Rio de Janeiro: E. \& H. Laemmert, 1857, t. 2.

WEHLING, Arno; WEHLING, Maria José Mesquita Cavalleiro de Macedo. Formação do Brasil colonial. Rio de Janeiro: Nova Fronteira, 1994.

WEHLING, Maria José Mesquita Cavalleiro de Macedo. O Estado do Maranhão na União Ibérica. Revista do Instituto Histórico e Geográfico Brasileiro, Rio de Janeiro, v. 166, n. 426, p. 57-86, jan./mar. 2005. 